Article

\title{
Raman Spectroscopy as an Assay to Disentangle Zinc Oxide Carbon Nanotube Composites for Optimized Uric Acid Detection
}

\author{
Shawtik C. Das, Raja R. Pandey, Tuphan Devkota $\mathbb{D}$ and Charles C. Chusuei *D \\ Chemistry Department, Middle Tennessee State University, Murfreesboro, TN 37130, USA; \\ sdas@shealylab.com (S.C.D.); RajaRam.Pandey@mtsu.edu (R.R.P.); tdevkota@nd.edu (T.D.) \\ * Correspondence: Charles.Chusuei@mtsu.edu; Tel.: +1-615-898-2079
}

Received: 26 October 2018; Accepted: 6 December 2018; Published: 12 December 2018

check for updates

\begin{abstract}
Refluxed zinc oxide ( $\mathrm{ZnO})$ nanoparticles (NPs) were prepared and attached to carboxylic acid functionalized multi-walled carbon nanotubes (COOH-MWNTs) via sonication. Practical optimization of electrocatalysts using sonication to disentangle a carbon nanotube composite for monitoring uric acid (UA) is shown. Monitoring UA is important for the management of medical disorders. Selection of sonication time is a crucial step in producing the desired composite. We report, for the first time, the practical use of Raman spectroscopy to tune the sonication involved in tethering $\mathrm{ZnO}$ NPs to the multi-walled carbon nanotube (MWNT) surface. Maximum current for detecting $\mathrm{UA}$, using chronoamperometry and cyclic voltammetry, correlated with the highest $\mathrm{sp}^{2}$-hybridized carbon signal, as seen in the integrated Raman $\mathrm{G}$ band peak areas denoting maximum COOH-MWNT disentanglement. An array of $\mathrm{ZnO} / \mathrm{COOH}-\mathrm{MWNT}$ composites were prepared ranging from 60 to $240 \mathrm{~min}$ sonication times. Optimum sonication $(150 \mathrm{~min}$ ) corresponded with both maximum measured current and MWNT disentanglement. The sensor was able to quantitatively and selectively measure UA at clinically relevant concentrations $(100-900 \mu \mathrm{M})$ with rapid current response time $(<5 \mathrm{~s})$.
\end{abstract}

Keywords: Raman spectroscopy; electrochemical sensing; zinc oxide nanoparticles; multi-walled carbon nanotubes; chronoamperometry; cyclic voltammetry

\section{Introduction}

Uric acid (UA) is a byproduct of purine metabolism and its monitoring is important for management of medical disorders. Its overproduction, that is, hyperuricemia, often signals kidney dysfunction. Elevated serum UA concentrations have been strongly linked to hypertension [1,2], coronary heart disease [2], kidney stones [3], gout [4], Lesch-Nyhan syndrome [5], cardiovascular and kidney disease via impairment of endothelial integrity and function $[2,6,7]$, and is one of the most reliable predictors of diabetes. An increase in UA levels typically precedes the development of both insulin resistance and Type 2 diabetes [7]. It has been shown that lowering uric acid in blood serum to levels at least below $6 \mathrm{mg} / \mathrm{dL}$ results in the disappearance of the clinical features of gout $[8,9]$. Gout patients, whose conditions result from elevated UA in blood $[9,10]$, are susceptible to cardiovascular risk factors [2,10-12].

Conventional UA assaying methods, for example, liquid chromatography mass spectrometry (LC-MS) and high performance liquid chromatography (HPLC) [13], often require time-consuming analysis of blood and urine, during which many of these pathologies can escape diagnosis. Hence, improved methods for rapid, accurate UA concentration monitoring are needed. The development of electrochemical electrode composites for improved UA sensing is an active area of research [14-20]. The state-of-the-art UA sensing composite employs precious metals in its fabrication [21]. Due to 
limitations of resources, sensors employing earth-rich materials that can be facilely fabricated are desirable. One such type of material is zinc oxide $(\mathrm{ZnO}) . \mathrm{ZnO}$ is an n-type semiconductor. Because of its wide band gap (3.37 eV), relatively high conductivity, excitation binding energy (60 eV), and high breakdown strength, the material is an attractive candidate for biosensing applications [22,23], and has been shown to be effective in the quantitative detection of UA. A detailed review of UA sensors is given elsewhere [24].

Carbon nanotube composites offer new avenues for practical electrocatalyst preparation. Multi-walled carbon nanotubes (MWNTs) have been shown to serve as effective supports for tethering electrocatalytically active nanoparticles (NPs), thereby improving even distribution for a host of electrochemical sensing applications [14]. Cavitation offered by sonication is often employed to maximize the even distribution of electrocatalytically active NPs [25,26]. A challenge in optimizing carbon nanotube based electrocatalysts is controlling the degree of dispersion and uniformity of the tethered ZnO NPs to maximize redox signal. The composite's relatively less-defined morphology as a result of carbon nanotube entanglement affects the degree of exposed electroactive surface area. Too little sonication and the NPs sparsely attach to the MWNT sidewalls and remain insufficiently distributed. Excessive sonication results in surface damage to carboxylic acid ( $\mathrm{COOH})$ acid moiety tethering points that would result in agglomeration of the NPs, leading to reduced electrocatalytic activity [27]. Our laboratory has applied this same principle of optimized sonication for tethering $\mathrm{ZnO}$ NPs for various analyte sensing applications [16,28].

An overlooked variable for material preparation is adjusting the MWNT surface entanglement itself, which can be achieved via adjusting sonication time. We show in this report, for the first time, the utility of Raman spectroscopy for assaying various $\mathrm{ZnO} / \mathrm{COOH}-\mathrm{MWNT}$ composites produced by varying sonication times, in particular, to optimize the sensitivity of the ZnO/COOH-MWNT composite for detecting UA. Rapid D-to-G band ratio monitoring permits facile identification of the optimum sonication time for electrocomposite preparation to achieve maximum sensing performance. This monitoring technique may prove to be universally applicable to optimize a host of electrochemical sensors (to detect and measure any analyte) that employ the attachment of nanoparticles to $\mathrm{COOH}$-functionalized carbon nanotube surfaces for its fabrication. In this study, the Raman $\mathrm{G}$ band integrated peak areas are used to quantify the degree of exposed $\mathrm{sp}^{2}$-hybridized carbon, denoting carbon nanotube disentanglement affecting the electrocatalyst's sensitivity for UA sensing.

\section{Materials and Methods}

\subsection{Materials}

Bamboo structure COOH-MWNTs (95\% purity, $30 \mathrm{~nm}$ diam) were purchased from Nanolab, Inc. (Waltham, MA, USA), and were used as received. Reagent grade (99\% purity) UA, phosphate buffer solutions (PBS, $\mathrm{pH}=7.0$ ), dopamine (DA), acetaminophen (AP), zinc nitrate hexahydrate (98\% purity), L-ascorbic acid (AA) (99\%) and folic acid (FA) were all purchased from Sigma-Aldrich (St. Louis, MO, USA). Hydrogen peroxide $\left(\mathrm{H}_{2} \mathrm{O}_{2}\right)(30 \mathrm{wt}$. \%) and $\mathrm{NaOH}$ were purchased from Fischer Scientific (Fair Lawn, NJ, USA). Absolute anhydrous ethyl alcohol (AAEA) was obtained from Pharmco-AAPER (Shelbyville, KY, USA). Nafion ${ }^{\mathrm{TM}}$ binder was purchased from Ion Power, Inc. (New Castle, DE, USA). All solutions were prepared using Millipore water $(18 \mathrm{M} \Omega \cdot \mathrm{cm})$.

\subsection{Nanocomposite Synthesis}

A series of nanocomposites incorporated onto glassy carbon electrode (GCE) surfaces for electrochemical analysis of UA via Nafion film were synthesized using two steps: (i) refluxed synthesis of $\mathrm{ZnO}$ nanostructures, followed by (ii) attachment to COOH-MWNTs. Refluxed ZnO NPs were synthesized following a procedure developed by Fang et al. [29]. A 20-mL volume of $1 \mathrm{M} \mathrm{NaOH}$ was added into a round bottle flask. A separatory funnel containing $0.5 \mathrm{M}$ of $20 \mathrm{~mL}$ of $\mathrm{Zn}\left(\mathrm{NO}_{3}\right)_{2} \cdot 6 \mathrm{H}_{2} \mathrm{O}$ was attached to the flask. The $\mathrm{NaOH}$ solution was heated to $100{ }^{\circ} \mathrm{C}$, while 
$\mathrm{Zn}\left(\mathrm{NO}_{3}\right)_{2} \cdot 6 \mathrm{H}_{2} \mathrm{O}$ was added dropwise for 60 min under continuous stirring (with a magnetic stirrer) under inert $\mathrm{N}_{2}$ atmosphere to obtain the ZnO NPs. Refluxing under these conditions continued for an additional $2 \mathrm{~h}$ at $100{ }^{\circ} \mathrm{C}$. After obtaining white precipitation, $\mathrm{ZnO}$ was filtered and washed with Millipore water. After several washings, the obtained NPs were dried in a desiccator overnight. The $\mathrm{ZnO}$ NPs were dried in an oven for one hour at $65^{\circ} \mathrm{C}$. To fabricate the $\mathrm{ZnO} / \mathrm{COOH}-\mathrm{MWNT}$ electrocatalyst composite, $2.0 \mathrm{mg}$ of the refluxed $\mathrm{ZnO}$ and $2.0 \mathrm{mg}$ of the COOH-MWNTs in $1.0 \mathrm{~mL}$ AAEA solvent were placed in a polyethylene tube and sonicated at preselected times. An array of $\mathrm{ZnO} / \mathrm{COOH}-\mathrm{MWNT}$ composites were produced, varying sonication times at 60, 90, 120, 150, 165,180 and $240 \mathrm{~min}$, for each electrocatalyst. A direct reduction of electroactive surface area was measured with reduced $\mathrm{G}$ band intensity to validate this correlation (vide infra). The resulting $\mathrm{ZnO}$ nanostructures were tethered to the $\mathrm{COOH}$ groups as verified by the disappearance of the carboxylate symmetric and asymmetric peaks in the ATR-IR [16], also observed in our laboratory with other NPs [27]. Each ZnO/COOH-MWNT nanocomposite was drop-casted onto glassy carbon electrodes (GCE), $5 \mathrm{~mm}$ in diam. A 10- $\mu \mathrm{L}$ colloidal aliquot of the composite as a colloidal suspension was pipetted onto the GCE surface. The GCE was then placed into the oven for $15 \mathrm{~min}$ at $80^{\circ} \mathrm{C}$. After drying, a second $10-\mu \mathrm{L}$ aliquot of $2 \%$ Nafion solution was added on top, and dried in an oven at $80{ }^{\circ} \mathrm{C}$ for additional $15 \mathrm{~min}$ to obtain the Nafion/ZnO/COOH-MWNTs/GCE sensor.

\subsection{Characterization}

Cyclic voltammetry $(\mathrm{CV})$ and chronoamperometry $(\mathrm{CA})$ were performed using WaveNano ${ }^{\mathrm{TM}}$ potentiostat software (Pine Instruments, Inc.; Durham, NC, USA). Electrochemical experiments were performed in a 3-electrode electrochemical cell system consisting of a $\mathrm{Pt}$ wire auxiliary electrode, an $\mathrm{Ag} / \mathrm{AgCl}(3.5 \mathrm{M} \mathrm{KCl})$ reference electrode, and a glassy carbon electrode modified with a $\mathrm{ZnO} / \mathrm{COOH}-\mathrm{MWNT}$ composite as the working electrode. The electrochemistry medium was PBS $(\mathrm{pH}=7.0)$. All experiments were performed in a deoxygenated electrolyte solution prepared by bubbling $99.9 \%$ purity $\mathrm{N}_{2}$ gas flow (Air Gas Products, Radnor, PA, USA) through the solution for $15 \mathrm{~min}$ prior to each measurement. The solution was bubbled with $\mathrm{N}_{2}$ at room temperature $\left(22 \pm 1{ }^{\circ} \mathrm{C}\right)$ inside a copper-grid Faraday cage. CVs were carried out between potentials ranging from -1.00 to $+1.00 \mathrm{~V}$ at a scan rate of $50 \mathrm{mV} \cdot \mathrm{s}^{-1}$. Raman spectroscopy was performed using an Enwave Optronics ProRaman-L spectrometer with a $500 \mathrm{~mW}$ Class 3B laser $(\lambda=785 \mathrm{~nm})$. Raman samples were prepared by pipetting colloidal suspensions of the $\mathrm{ZnO} / \mathrm{COOH}-\mathrm{MWNT}$ in absolute anhydrous ethanol onto $\mathrm{Si}(100)$ wafers. X-ray photoelectron spectroscopy (XPS) was carried out using a Perkin-Elmer PHI 560 spectrometer with a double-pass cylindrical mirror analyzer operated at $225 \mathrm{~W}$ and $13 \mathrm{kV}$ using a $\mathrm{Mg}$ $\mathrm{K} \alpha(\mathrm{h} v=1253.6 \mathrm{eV})$ anode, with narrow scans acquired using a $50 \mathrm{eV}$ pass energy. The optimized composite sample was analyzed as a solid applied to double-sided electrically conductive tape (Ted Pella Inc., Redding, CA, USA), which was outgassed via a turbo-pumped antechamber. TEM was carried out using a Hitachi H-7650 microscope operated at $100 \mathrm{kV}$, applying the colloidal samples to a 200-mesh copper grids. The procedure of isoelectric point measurements, involving $\mathrm{pH}$ measurements with a spear-tipped electrode, have been described elsewhere for experiments involving carbon nanomaterial composites [30-35]. Briefly, $\mathrm{pH}$ solutions varying in values from 1 to 12 were prepared, to which $2.0 \mathrm{mg}$ of the solid material were introduced. After $16 \mathrm{~h}$ equilibration periods, the final $\mathrm{pH}$ was measured, resulting in observed plateaus in the initial versus final $\mathrm{pH}$ plots that denote the isoelectric points for each solid. Plots of initial versus final $\mathrm{pH}$ revealed plateaus, denoting the point-of-zero (PZC) charge of the electrocatalyst.

\section{Results and Discussion}

XPS signals of O 1s, C 1s, and $\mathrm{Zn} \mathrm{2p}$ orbitals were detected in the $\mathrm{ZnO} / \mathrm{COOH}-\mathrm{MWNT}$ nanocomposites. The composite produced using a $150 \mathrm{~min}$ sonication time was found to have the highest electrocatalytic activity, as shown in Figure 1. There was no variation or trend in XPS scans between composites prepared at different sonication times (60 to $240 \mathrm{~min}$ ). High-resolution peaks were 
deconvoluted from the XPS narrow scans to analyze using CasaXPS ${ }^{\mathrm{TM}}$ VAMAS curve-fitting software 2.2.107 (Devon, UK). The atomic percent composition measured from the $\mathrm{C} 1 \mathrm{~s}, \mathrm{O} 1 \mathrm{~s}$, and $\mathrm{Zn} 2 \mathrm{p}$ orbitals after normalizing their integrated peak areas to their atomic sensitivity factors were $93.1 \%, 5.2 \%$, and $1.7 \%$, respectively. The $\mathrm{C} 1 \mathrm{~s}$ binding energy $(\mathrm{BE})$ at $284.4 \mathrm{eV}$ was used as a charge reference denoting $\mathrm{sp}^{2}$-hybridized $\mathrm{C}$ from the carbon nanotube graphene sheets [36].

Figure $1 \mathrm{~B}$ shows the $\mathrm{O}$ 1s XPS spectrum for $\mathrm{ZnO} / \mathrm{COOH}-\mathrm{MWNT}$. The $\mathrm{O}$ 1s core levels of the composite shows two major peaks: one at $531.1 \mathrm{eV}$, which we assign to $-\mathrm{C}=\mathrm{O}$ from the thered $\mathrm{COOH}$ moieties to the MWNT surface [26]. The other peak at $532.2 \mathrm{eV}$, which corresponds to adsorbed hydroxyl oxygen [37], is obtained during its synthesis from exposure to aqueous solution. The O 1 s BE at $532.1 \mathrm{eV}$ instead is indicative of adsorbed interstitial $\mathrm{OH}$ in vacant sites within the $\mathrm{ZnO}$ [38]. The $\mathrm{C}$ 1s BE peak at $285.8 \mathrm{eV}$ denotes a polymeric C-O structure due to the presence of - $\mathrm{COOH}$ units [39]. The XPS spectrum of Zn $2 \mathrm{p}$ orbital in Figure $2 \mathrm{C}$ shows a doublet separation of $2 \mathrm{p}_{3 / 2}$ and $2 \mathrm{p}_{1 / 2}$ orbitals at 1045.1 and $1022.4 \mathrm{eV}$ is $22.7 \mathrm{eV}$, matching the literature values for $\mathrm{ZnO}$ [40,41]. The oxidation state for pure metal oxide O, expected at $\sim 530 \mathrm{eV}$ for ZnO NPs [34,35,42], is greatly attenuated by adsorbed $\mathrm{OH}$ overlayers and not readily resolved. The greatly attenuated $\mathrm{O} 1 \mathrm{~s}$ metal oxide oxidation state signal is also consistent with the low atomic \% $\mathrm{Zn} 2 \mathrm{p}$ observed, that is, the $\mathrm{OH}$ overlayers also attenuate the $\mathrm{ZnO}$ signal. The red arrow in Figure $1 \mathrm{~A}$ denotes the attenuated BE position of the $\mathrm{ZnO}$ oxidation state.

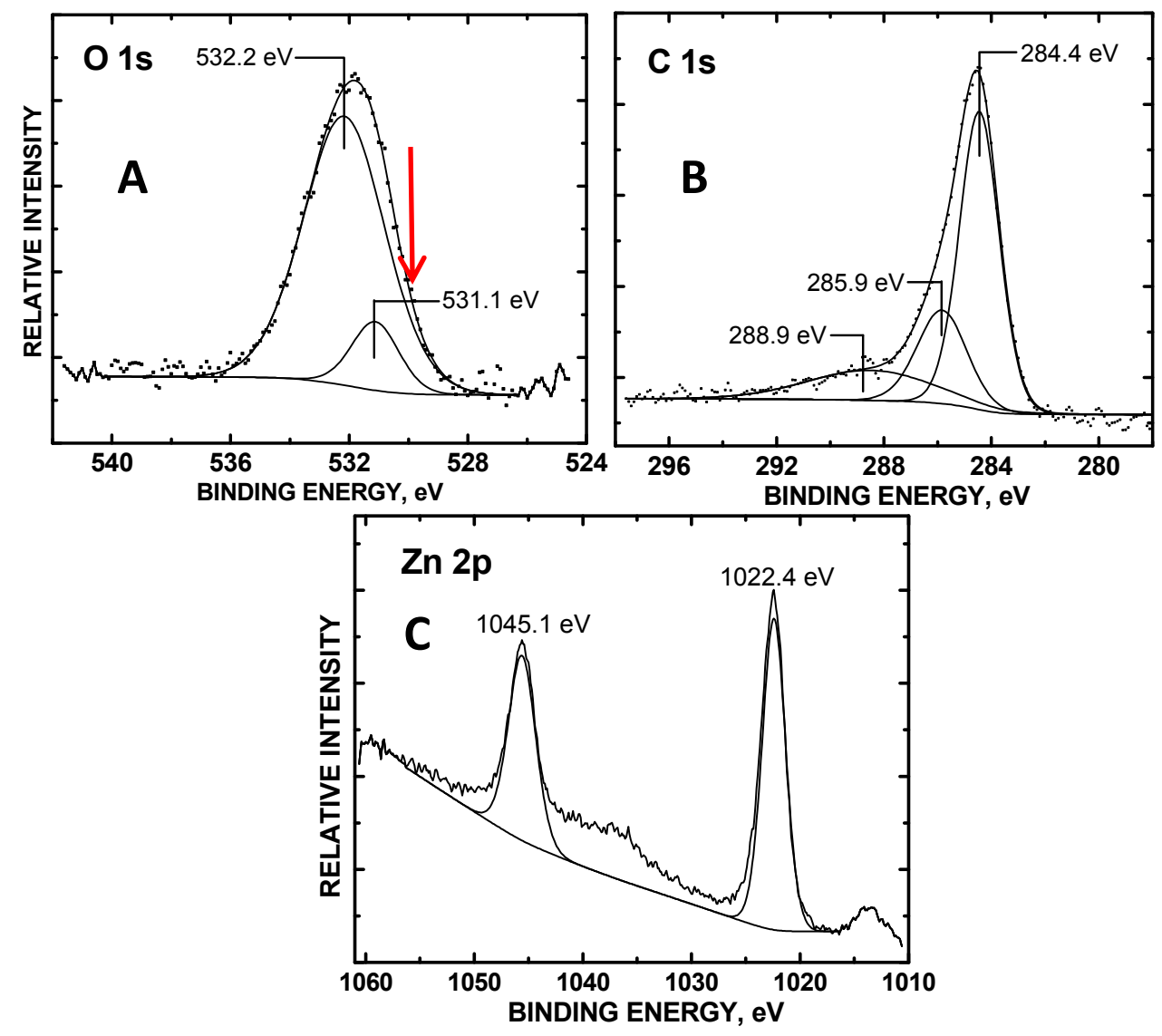

Figure 1. XPS narrow scans of the (A) O 1s, (B) C 1s, and (C) Zn 2p orbitals of the 150 sonicated refluxed $\mathrm{ZnO} /$ carboxylic acid functionalized multi-walled carbon nanotube (COOH-MWNT) composite. The red arrow in (A) denotes the BE position of $\mathrm{ZnO}$ oxidation state.

The lowered $\mathrm{O}$ 1s BE peak center at $531.1 \mathrm{eV}$ (relative to $531.3 \mathrm{eV}$ ) [26], denoting $-\mathrm{C}=\mathrm{O}$, can be attributed to extra-atomic relaxation of the $\mathrm{O} 1 \mathrm{~s}$ photoelectrons due to interactions with the tethered $\mathrm{ZnO}$ NPs. Signals from the deconvoluted O 1s XPS BE showed a 0.87:0.13 ratio of adsorbed OH to interstitial $\mathrm{OH}$ within the $\mathrm{ZnO} / \mathrm{COOH}-\mathrm{MWNT}$ composite surface (Figure 1A). 
Figure 2 shows $\mathrm{CV}$ scans for each of the $\mathrm{ZnO} / \mathrm{COOH}-\mathrm{MWNT}$ composites during redox cycles of $10 \mathrm{mM}$ UA with increasing sonication times from 0 to $240 \mathrm{~min}$. The zero sonication time denotes the electrode surface reaction with the COOH-MWNT surface only and without attached ZnO NPs, which was used as a control. The CV of UA shows a distinct oxidation peak at $+0.5 \mathrm{~V}$ vs. $\mathrm{Ag} / \mathrm{AgCl}$ $(3.5 \mathrm{M} \mathrm{KCl})$. The oxidation peaks are in agreement with previous $\mathrm{ZnO}$-carbon nanotube based electrochemical sensing composite measurements [16]. Increased peak heights in the CVs denote increased electrocatalytic activity. The peak current heights along with voltages are summarized in Table 1. Randles-Sevcik (RS) analysis was performed for all of the composites, varying the scan rates from 10 to $100 \mathrm{mV} \cdot \mathrm{s}^{-1}$. The asymmetrical shape indicates that the $\mathrm{CV}$ redox reaction is irreversible. The CV shown at 0 min (Figure 2) denotes the electrocatalytic activity of the bare COOH-MWNT surface without attached ZnO NPs; the reduction current observed was $36 \mu \mathrm{A}$. A control CV for the $\mathrm{ZnO}$ NPs only is shown in Figure S1 (in the Supplementary Materials); the observed reduction current was $45 \mu \mathrm{A}$. The control CV for the refluxed $\mathrm{ZnO}$ NPs applied to the bare GCE surface shows a mere $45 \mu \mathrm{A}$ reduction signal for UA under these same $\mathrm{pH} 7.0$ conditions, which is markedly less current as compared to the 150 min sonicated $\mathrm{ZnO} / \mathrm{COOH}-\mathrm{MWNT}$ composite.
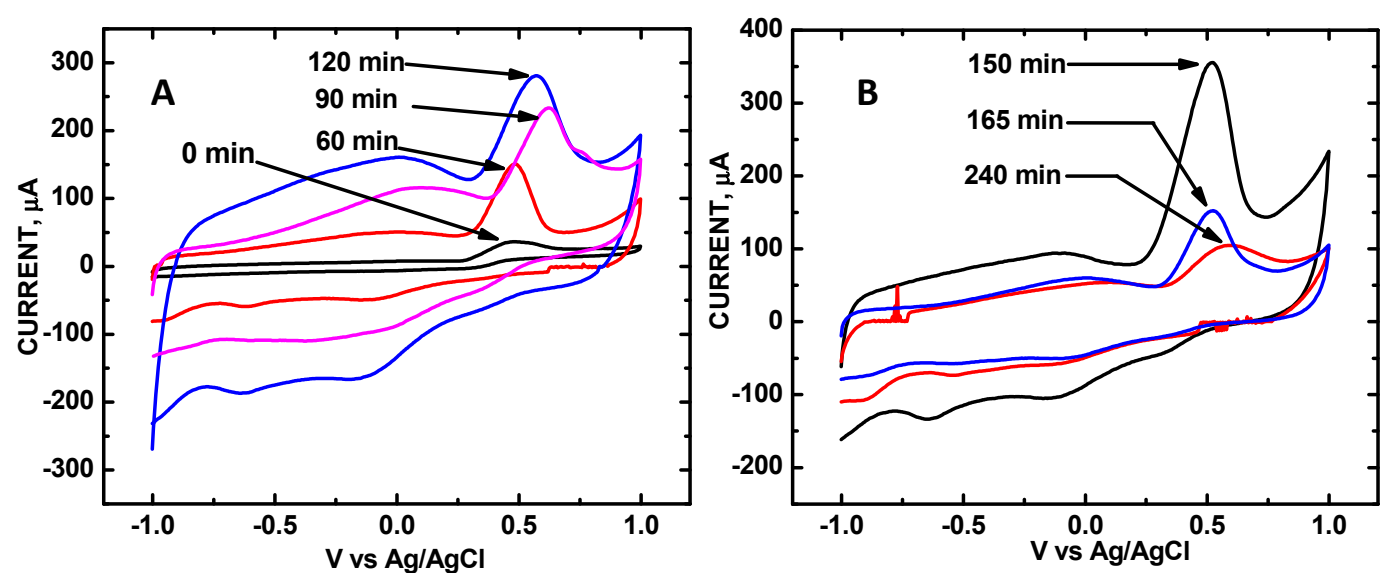

Figure 2. Cyclic voltammetry (CV) of $10 \mathrm{mM}$ UA in PBS ( $\mathrm{pH}=7.0)$ from $\mathrm{ZnO} / \mathrm{COOH}-\mathrm{MWNT}$ composites produced at sonication times of (A) 0 (control), 60, 90, and $120 \mathrm{~min}$; and (B) 150, 165, and $240 \mathrm{~min}$. Scan rate: $50 \mathrm{mV} \cdot \mathrm{s}^{-1}$.

Table 1. CV current peak heights and voltages of $\mathrm{ZnO} / \mathrm{COOH}-\mathrm{MWNTs}$.

\begin{tabular}{ccccccccc}
\hline Sonication Time, $\mathbf{m i n}$ & $\mathbf{0}$ & $\mathbf{6 0}$ & $\mathbf{9 0}$ & $\mathbf{1 2 0}$ & $\mathbf{1 5 0}$ & $\mathbf{1 6 5}$ & $\mathbf{1 8 0}$ & $\mathbf{2 4 0}$ \\
\hline $\mathrm{V}$ & 0.500 & 0.499 & 0.623 & 0.571 & 0.524 & 0.520 & 0.534 & 0.524 \\
$\mu \mathrm{A}$ & 36 & 149 & 233 & 281 & 355 & 153 & 133 & 106 \\
relative area & 0 & 1.00 & 1.56 & 1.87 & 2.38 & 1.07 & 0.892 & 0.698 \\
\hline
\end{tabular}

The CV current follows the RS relation for a quasi-reversible reaction [43]:

$$
\mathrm{i}_{\mathrm{p}}=2.99 \times 10^{5} \mathrm{n}(\alpha \mathrm{n})^{1 / 2} \mathrm{~A} \cdot \mathrm{C}^{\circ} \cdot \mathrm{D}^{1 / 2} \cdot \mathrm{v}^{1 / 2}
$$

where $\mathrm{n}$ is the number of electrons, A the electrode area $\left(\mathrm{in} \mathrm{cm}^{2}\right), \mathrm{C}^{\circ}$ the concentration $\left(\mathrm{mol} \cdot \mathrm{cm}^{-3}\right)$, $\mathrm{D}$ the diffusion coefficient $\left(\mathrm{cm}^{2} \cdot \mathrm{s}^{-1}\right)$, and $\mathrm{v}$ the scan rate $\left(\mathrm{V} \cdot \mathrm{s}^{-1}\right)$. Plots of measured current versus the square root of the scan rate were linear for all of the prepared $\mathrm{ZnO} / \mathrm{COOH}-\mathrm{MWNT}$ composites with least square correlation coefficient $\mathrm{R}^{2}$ values of 0.94 or higher (Figures S2-S8 in the Supplementary Materials), indicating diffusion controlled processes at the electrode surface. The relative electroactive surface area (relative area) in Table 1 was calculated by algebraic comparison of RS equations with respect to the relative electroactive surface area of the $60 \mathrm{~min}$ sonicated $\mathrm{ZnO} / \mathrm{COOH}-\mathrm{MWNT}$ composite. For instance, RS equations for the 60 and 90 min sonicated composites are shown in Equations (2) and (3), respectively: 


$$
\begin{aligned}
& \mathrm{i}_{\mathrm{p} 60}=0.149 \times 10^{-3} \mathrm{~A}=2.99 \times 10^{5} \mathrm{n}(\alpha \mathrm{n})^{1 / 2} \mathrm{~A}_{60} \mathrm{C}^{\circ} \mathrm{D}^{1 / 2} \mathrm{v}^{1 / 2} \\
& \mathrm{i}_{\mathrm{p} 90}=0.233 \times 10^{-3} \mathrm{~A}=2.99 \times 10^{5} \mathrm{n}(\alpha \mathrm{n})^{1 / 2} \mathrm{~A}_{90} \mathrm{C}^{\circ} \mathrm{D}^{1 / 2} \mathrm{v}^{1 / 2}
\end{aligned}
$$

Dividing Equation (3) by Equation (2) and arranging algebraically yields $A_{90} / A_{60}=1.56$ as the relative surface area in Table 1.

Cavitation provided by sonication enhances the tethering of the ZnO NPs to the COOH-MWNT surface and disentangles the MWNTs to maximize the electroactive surface area. Hence, measured current could directly be used to quantify relative electroactive surface area (Table 1). Employing RS analysis (varying the scan rates for 60 to $240 \mathrm{~min}$ sonicated composites yields 7 independent equations for comparison), relative electroactive surface areas were calculated by normalizing the area for the $60 \mathrm{~min}$ sonicated composite as 1.00. As sonication proceeded from 0 to $240 \mathrm{~min}$, an increase followed by a decrease in electroactive surface area is observed with highest surface area. Maximum electrocatalytic activity was attained at $150 \mathrm{~min}$ of sonication, which is in excellent correlation with the Raman data (vide infra). For example, in comparing currents listed in Table 1, a 2.4-fold increase in the electroactive surface area, and hence sensitivity, is observed when comparing the $150 \mathrm{~min}$ sonicated $\mathrm{ZnO} / \mathrm{COOH}-\mathrm{MWNT}$ composite with that of $60 \mathrm{~min}$, that is, $355 \div 149 \approx 2.4$. We attribute the enhanced electrochemical activity for UA oxidation to the greater electrode surface area resulting from the largest degree of disentanglement produced by sonication.

Figure 3 shows TEM images of the $\mathrm{ZnO} / \mathrm{COOH}-\mathrm{MWNT}$ composites produced at varying sonication times of 60, 120, 150 and $165 \mathrm{~min}$. The composite becomes disentangled with increasing sonication times, with the 150 min sonicated composite having the most disentanglement with the lowest number of overlapping MWNT strands. The composite becomes disentangled with increasing sonication time, with the 150 min sonicated composite (Figure 3C) having the most disentanglement. As sonication ensues beyond the $150 \mathrm{~min}$ time point, the composite becomes more entangled. The trend in disentanglement observed coincides with increasing and decreasing Raman G band intensity (vide infra) along with measured electrochemical signals for UA. The average ZnO NP size maximized at $150 \mathrm{~min}$ of sonication. The degree of electrocatalytic activity for UA detection, instead, is predominantly governed by carbon nanotube disentanglement within the composite.

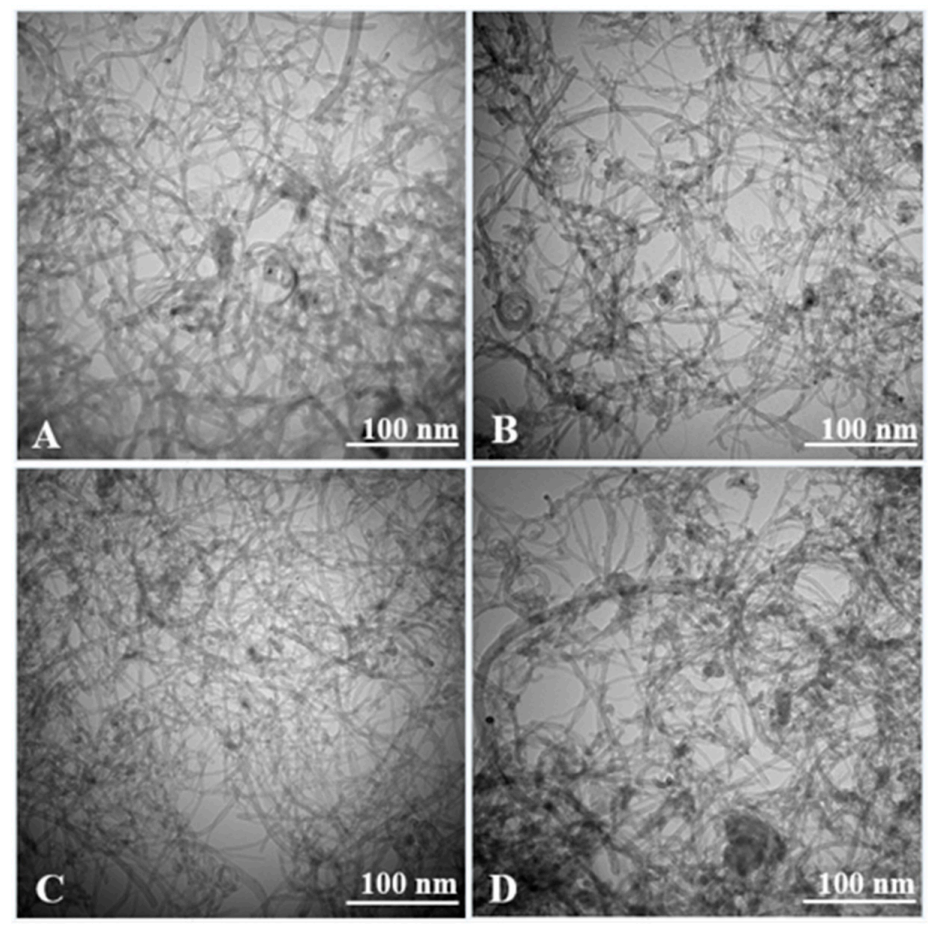

Figure 3. TEM images of refluxed ZnO/COOH-MWNTs nanocomposites produced at (A) 60, (B) 120, (C) 150, and (D) 165 min sonication times. The scale bar denotes a $100 \mathrm{~nm}$ length. 
Size histograms of the ZnO NP diam are shown in Figure 4 along with Gaussian fit overlays. The average diam \pm STD for the ZnO NPs at $60,120,150$, and 165 min sonication times was $12.7_{2} \pm 0.2_{1}$, $12.3_{5} \pm 0.3_{7}, 14.2_{5} \pm 0.2_{5}$ and $12.7_{8} \pm 0.3_{8} \mathrm{~nm}$, respectively. The $150 \mathrm{~min}$ sonicated composite had the largest average diameter and the most even size distribution, as compared to the other composites, as shown by the $\mathrm{R}^{2}$ values. The average $\mathrm{ZnO}$ NP size maximized at 150 min of sonication.
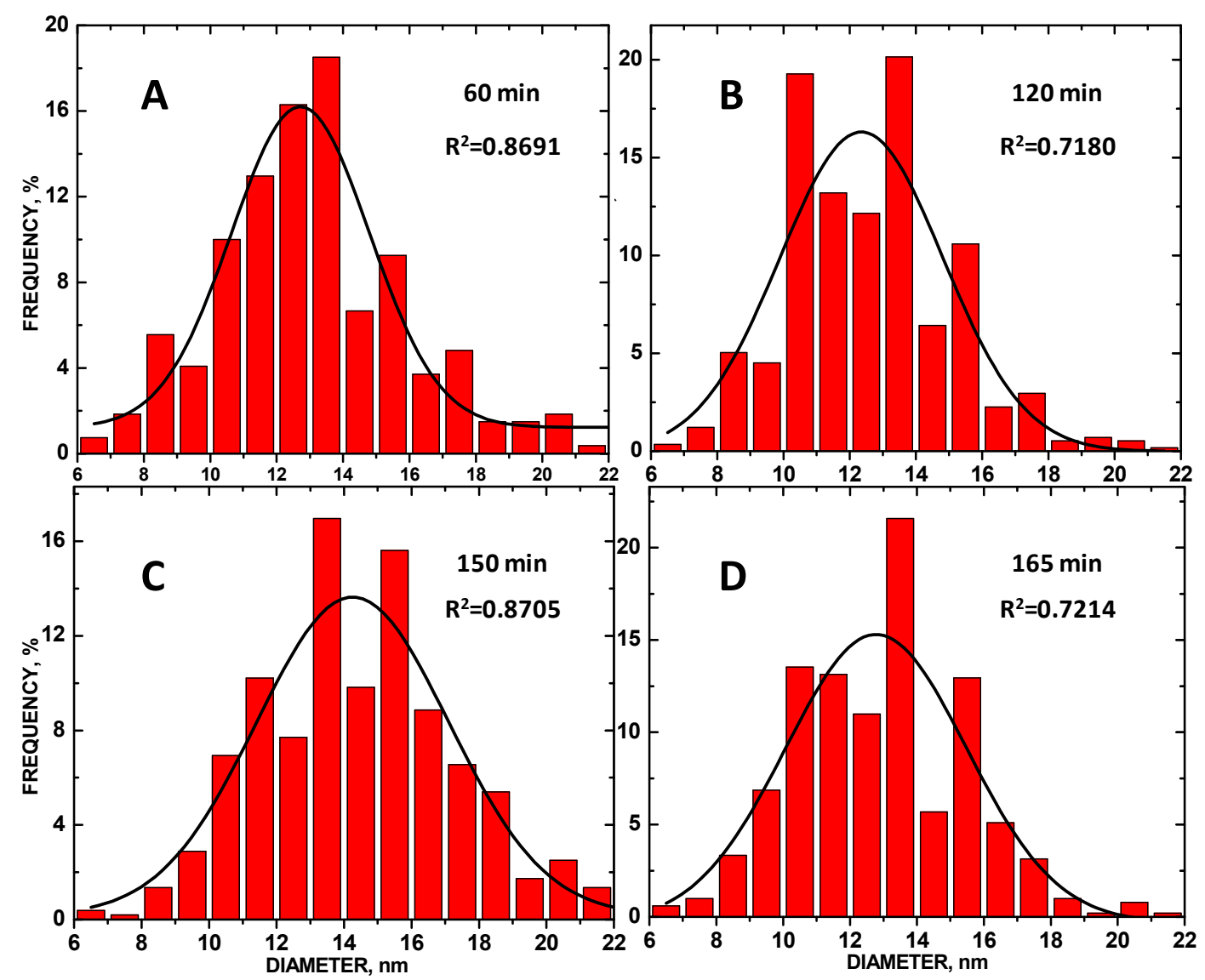

Figure 4. Size histograms of tethered ZnO NPs tethered to the COOH-MWNT surface of the MWNTs, produced at (A) 60, (B) $120 \mathrm{~min}$, (C) 150, and (D) 165 min sonication times.

Raman shifts at 1320 and $1600 \mathrm{~cm}^{-1}$ (Figure 5), denoting the D and G bands, match those in the literature $[27,44]$, corresponding to the $\mathrm{sp}^{3}$ - and $\mathrm{sp}^{2}$-hybridized carbon atoms indicating disordered graphite and ordered graphene within the MWNTs, respectively, are shown for each composite in Figure 5A; raw data with offsets are shown. Integrated areas of the Raman D band also tracked well as a function of sonication time with maximum current at $150 \mathrm{~min}$, but had more scatter in the trend at other sonication times, likely due to $\mathrm{sp}^{3}$-hybridized carbon bond formation as a result of the creation of more sites to bind with $\mathrm{ZnO}$ during sonication. The degree of carbon nanotube disentanglement is directly quantified via integrated peak areas of the Raman $\mathrm{G}$ band, which denotes the amount of exposed $\mathrm{sp}^{2}$-hybridized carbon of the graphene sheet $[45,46]$. Since the $\mathrm{sp}^{2}$-hybridized carbon, represented by the G band, was never altered in the tethering of $\mathrm{ZnO} N P s$, the G band intensity better represents the degree of MWNT disentanglement than that of the D band. The more disentangled the $\mathrm{ZnO} / \mathrm{COOH}-\mathrm{MWNTs}$, the more $\mathrm{sp}^{2}$-hybridized carbon is exposed and the greater the electroactive surface area and Raman $G$ band intensity becomes. The integrated $G$ band peak area, calculated from the series of spectra in Figure 5A, increased from 60 to $150 \mathrm{~min}$, and then decreased from 150 to $240 \mathrm{~min}$ of sonication (Figure 5B, right-hand axis, blue trace). Sonication beyond $150 \mathrm{~min}$ resulted in re-entanglement of the MWNT support as indicated by the Raman spectra. This trend also corresponded with variations in measured current in the CVs. In Figure 5B, both maximum current 
and maximum $\mathrm{G}$ band area were observed at $150 \mathrm{~min}$, showing a direct correlation of analyte signal intensity with a fully disentangled $\mathrm{ZnO} / \mathrm{COOH}-\mathrm{MWNT}$ composite.
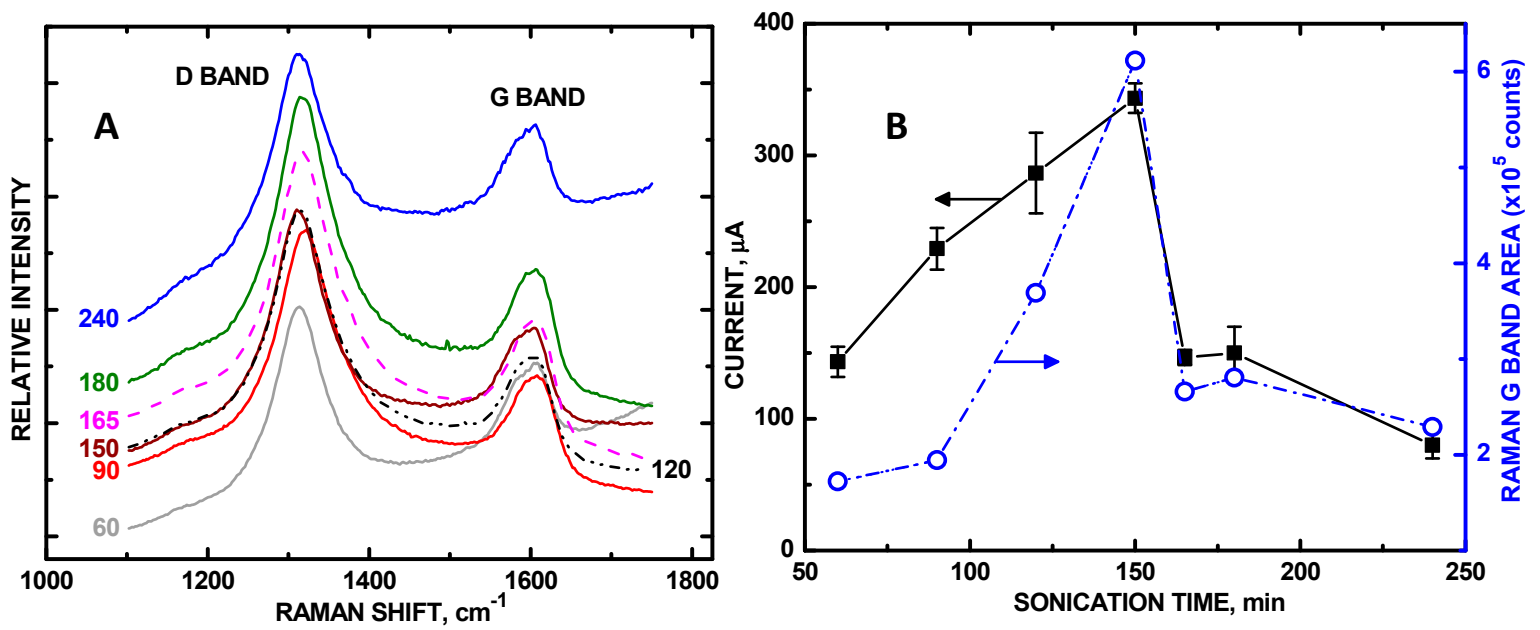

Figure 5. (A) Stack plot of Raman (raw) data with offset for 60, 120, 150 and 165 min showing diamond $\mathrm{D}$ and G bands, respectively; (B) potentiostat current of $10 \mathrm{mM}$ UA in PBS ( $\mathrm{pH}=7.0$ ) from CVs at $+0.577 \mathrm{~V}$ vs. Ag/ AgCl (left-hand axis) and Raman G band integrated peak area (right-hand axis).

The degree of disentanglement affected the size distribution of the tethered ZnO NPs. Of all of the $\mathrm{ZnO}$ NPs, the $150 \mathrm{~min}$ sonication produced the most even TEM size distribution in this series (Figure 4), which also correspond to highest electroactive surface areas as measured by RS analysis along with the most disentangled underlying MWNT substrate. Optimized sonication as observed by Raman spectroscopy resulted in a 9.8-fold increase in UA signal intensity. To our knowledge, this is the first systematic report monitoring the Raman $\mathrm{G}$ band intensity accompanying enhanced electrocatalytic activity. The closest related study is that of Wayu et al. [18], who employed sonication to tether $\beta$-cyclodextrin to $\mathrm{COOH}-\mathrm{MWNT}$ for UA sensing. In comparing the sensitivities with and without employing sonication, they reported a 3.7-fold increase in sensitivity to UA. We posit that the MWNT substrate disentanglement that occurred during their sonication step was responsible for this signal increase. A direct correlation of increased electrode UA signal with G band intensity denoting MWNT disentanglement was observed.

Our optimized $\mathrm{ZnO} / \mathrm{COOH}-\mathrm{MWNT}$ composite was also selective against an array of interfering analytes. Figure 6 shows quantitative CA measurements of UA, ranging from 100 to $900 \mu \mathrm{M}$ concentrations with current measurements obtained at a $+0.577 \mathrm{~V}$ in PBS $(\mathrm{pH}=7.0)$ under $\mathrm{N}_{2}$ bubbling. The $\mathrm{ZnO} / \mathrm{COOH}-\mathrm{MWNT} / \mathrm{GCE}$ electrode exhibited a linear response; the inset in Figure 6 shows the calibration curve $\left(\mathrm{R}^{2}=0.9821\right)$. The limit of detection based on CA was $2.3_{4} \pm 0.6_{3} \mu \mathrm{M}$. Normal UA levels in human blood are in the concentration range of $130-380 \mu \mathrm{M}(2.4 \mathrm{mg} / \mathrm{dL}$ to $7.0 \mathrm{mg} / \mathrm{dL})[47,48]$, which is well within the practical analysis range of our composite. In addition, the linearity range is capable of detecting UA levels marking the onset of health risk. The detection limit is comparable to those of Wayu et al. [18-20] of UA using a $\beta$-cyclodextrin-based electrocatalyst composite in place of the refluxed $\mathrm{ZnO} \mathrm{NPs}$. 


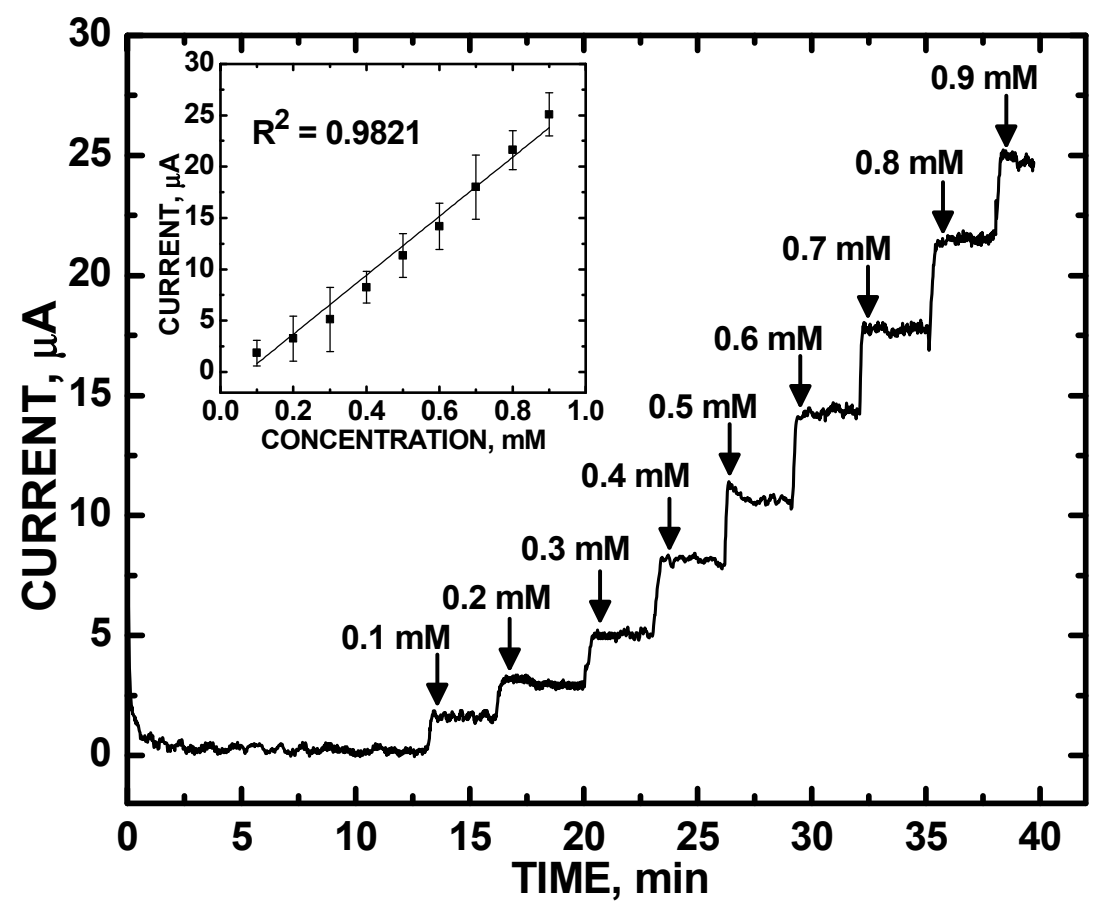

Figure 6. CA response of $\mathrm{ZnO} / \mathrm{COOH}-\mathrm{MWNT}$ in phosphate buffer solutions (PBS), upon addition of UA from 100-900 $\mu \mathrm{M}$; inset shows calibration curve.

Figure 7A shows the chronoamperometry response of $\mathrm{ZnO} / \mathrm{COOH}-\mathrm{MWNTs}$ modified glassy carbon electrode at $+0.577 \mathrm{~V}$ vs. $\mathrm{Ag} / \mathrm{AgCl}$ upon addition of $100 \mu \mathrm{M}$ concentrations of $\mathrm{UA}, \mathrm{H}_{2} \mathrm{O}_{2}, \mathrm{FA}$, $\mathrm{DA}, \mathrm{Glu}, \mathrm{AP}, \mathrm{AA}$ and UA, respectively. The $\mathrm{ZnO} / \mathrm{COOH}-\mathrm{MWNTs} / \mathrm{GCE}$ can selectively detect UA in the presence of FA, DA, AA, $\mathrm{H}_{2} \mathrm{O}_{2}$ and AP. Noteworthy is the fact that the introduction of $100 \mu \mathrm{M}$ of UA at the $970 \mathrm{~s}$ and $2012 \mathrm{~s}$ time points resulted in an observed CA signal for UA, but addition of FA, AA, DA, $\mathrm{H}_{2} \mathrm{O}_{2}$, and AP at 1138, 1307, 1488, 1645 and $1805 \mathrm{~s}$ time points resulted in no signal, showing selectivity. The selectivity of the composite can be accounted for by the differing isoelectric points of these analyte molecules.
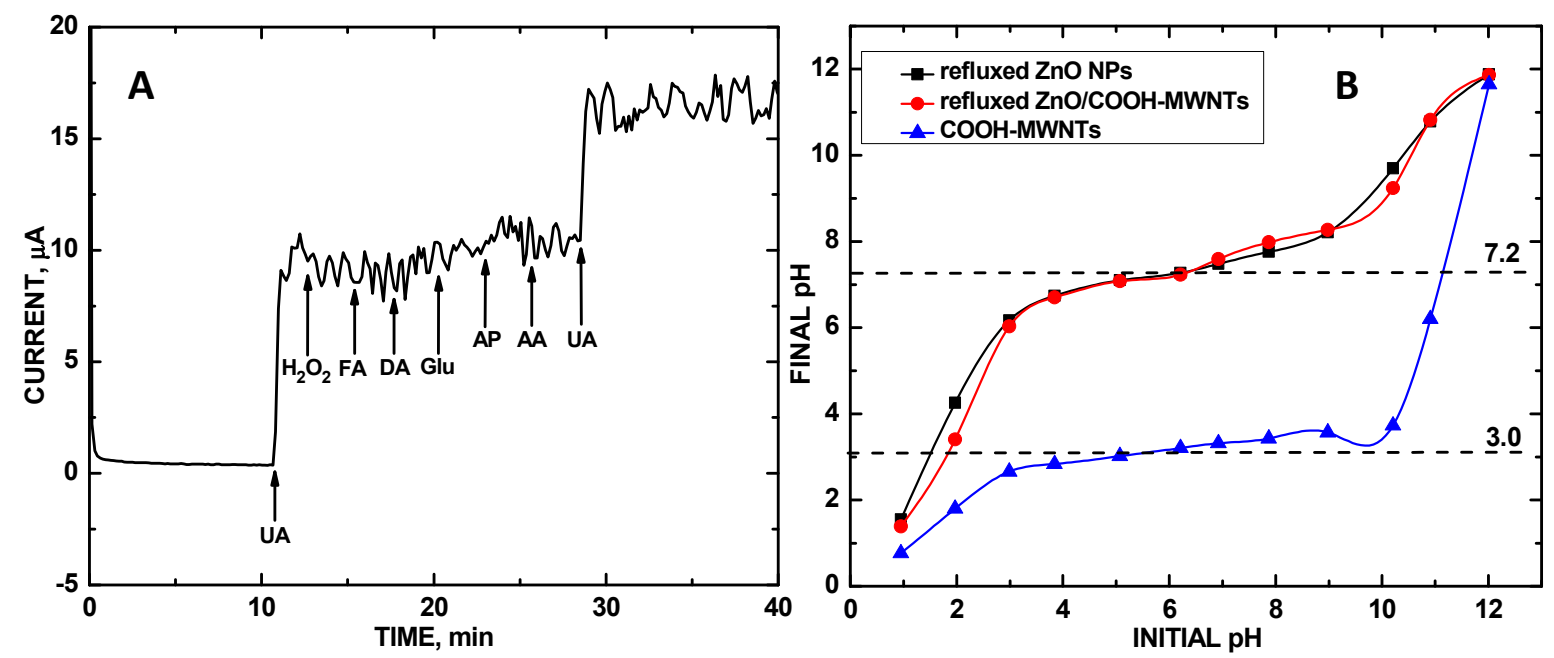

Figure 7. (A) CA response of the Nafion/ZnO/COOH-MWNTs/GCE at $0.577 \mathrm{~V}$ vs. $\mathrm{Ag} / \mathrm{AgCl}$ electrode upon $100 \mu \mathrm{M}$ additions of UA, FA, AA, DA, $\mathrm{H}_{2} \mathrm{O}_{2}$, AP, and UA, respectively; (B) point-of-zero (PZC)

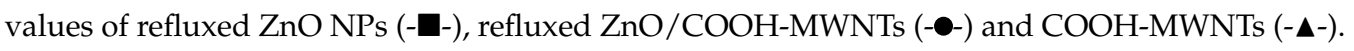


Figure 7B shows experimentally measured PZC values for the refluxed $\mathrm{ZnO} \mathrm{NPs}, \mathrm{ZnO} / \mathrm{COOH}-$ MWNTs, and COOH-MWNTs were found at 7.2, 7.2 and 3.0, respectively, as denoted by the plateaus of the initial versus final $\mathrm{pH}$ plot. Separately, the ZnO NPs and COOH-MWNTs have vastly different PZCs. However, when these two are combined, the composite adopts the same PZC as that of the tethered $\mathrm{ZnO}$ NPs. If the COOH-MWNTs were to remain unchanged by the ZnO NPs, the composite and all analytes would adopt a positive surface charge, repelling them from the electrode surface. The underlying rationale explaining why the tethered metal oxide NPs alter the composites overall surface charge is unclear and is a subject for future study. Under $\mathrm{pH}=7.0$ conditions, the $\mathrm{ZnO} / \mathrm{COOH}-\mathrm{MWNT}$ composite adopts a slightly positive surface charge due to greater surface protonation than hydroxylation according to electrical double layer theory [49]. With this series of analytes examined for selectivity, the $\mathrm{pK}_{\mathrm{a}}$ values of $\mathrm{UA}, \mathrm{AA}, \mathrm{FA}, \mathrm{AP}, \mathrm{H}_{2} \mathrm{O}_{2}$, and DA are 5.75 [3], $4.10\left(\mathrm{pK}_{1}\right) / 11.79\left(\mathrm{pK}_{2}\right)$ [50], 2.38 $\left(\mathrm{pK}_{1}\right) / 3.46\left(\mathrm{pK}_{2}\right) / 4.98\left(\mathrm{pK}_{3}\right) / 8.08\left(\mathrm{pK}_{4}\right)$ [51], 11.08 [52], 11.62 [53], and 8.93 [53], respectively. It should be noted that for AA and FA under $\mathrm{pH}=7.0$ conditions, the monoionic urate and folate forms of these species dominate, leaving the lower $\mathrm{pK}_{\mathrm{a}}$ values to be the dominant ones to governing molecular charge in solution. The AP and $\mathrm{H}_{2} \mathrm{O}_{2}$ molecules would be repelled from the electrode surface since they adopt positive charge at $\mathrm{pH}=7.0$. Hence, the resulting $\mathrm{ZnO} / \mathrm{COOH}-\mathrm{MWNT}$ composite is selective against these analytes. The acids UA, AA and FA, on the other hand, would adopt negative charges at this same solution condition and be Coulombically attracted to the sensing electrode. Selectivity, in this case, is governed by differing oxidation potentials of the analytes. Oxidation potentials for voltammetric detection of AA and FA using ZnO-carbon nanotube composites have been observed at ca. +0.2 [54] and $+0.9 \mathrm{~V}$ [55], respectively, which are well separated from that of UA oxidation at $+0.577 \mathrm{~V}$.

In summary, the results demonstrate a facile method for preparing an optimized $\mathrm{ZnO} / \mathrm{COOH}-\mathrm{MWNT}$ electrocatalyst material. Refluxed $\mathrm{ZnO}$ NPs were produced, followed by the attachment to $\mathrm{COOH}-\mathrm{MWNT}$ to form the $\mathrm{ZnO} / \mathrm{COOH}-\mathrm{MWNT}$ electrode composite for the selective and sensitive detection of UA, which had an effective measurement within the 100 to $900 \mu \mathrm{M}$ concentration range. For the first time, we have shown the utility of monitoring the Raman $G$ band to rapidly identify the surface produced by the cavitation process to create an optimized sensing composite. The optimized structure coincides with maximum electrocatalytic activity (Figure 5), with the most even size distribution of ZnO NPs tethered to the COOH-MWNT surface (Figures 3 and 4) permitting rapid detection of UA that is both quantitative (Figure 6) and selective (Figure 7). UA can be selectively detected in the presence of FA, DA, AA, $\mathrm{H}_{2} \mathrm{O}_{2}$, and AP. RS analysis revealed diffusion-controlled processes occurring on the electrode surface. During fabrication, $\mathrm{ZnO}$ NPs were attached via cavitation process afforded by sonication, while at the same time the underlying carbon nanotube support was disentangled the $\mathrm{ZnO} / \mathrm{COOH}-\mathrm{MWNTs}$, resulting in increased electroactive surface area and enhanced sensitivity for UA detection. The ideal sonication time (150 min) corresponded with the largest integrated Raman G band area, which can be readily monitored for optimization purposes.

A suggested preparation protocol would be to Raman scan an array of $\mathrm{ZnO} / \mathrm{COOH}-\mathrm{MWNT}$ composites prepared at different sonication times and the one yielding the largest $\mathrm{G}$ band would denote the optimum prepared composite for UA sensing. This approach of employing Raman analysis for electrocatalysis may well be universal for preparing various sensors for detecting and quantifying a host of other similar, pharmacologically related analytes.

Supplementary Materials: The following are available online at http:/ / www.mdpi.com/2227-9040/6/4/65/s1, Figure S1: CV of $10 \mathrm{mM}$ UA using only ZnO NPs, Figure S2: CVs and RS plot of $10 \mathrm{mM}$ UA with 60 min composite, Figure S3: CVs and RS plot of $10 \mathrm{mM}$ UA with $90 \mathrm{~min}$ composite, Figure S4: CVs and RS plot of $10 \mathrm{mM}$ UA with 120 min composite, Figure S5: CVs and RS plot of 10 mM UA with 150 min composite, Figure S6: CVs and RS plot of 10 mM UA with 165 min composite, Figure S7: CVs and RS plot of 10 mM UA with 180 min refluxed composite, Figure S8: CVs and RS plot of 10 mM UA with 240 min composite.

Author Contributions: Conceptualization, C.C.C.; Data Curation, S.C.D., T.D. and R.R.P.; Software, C.C.C.; Validation, S.C.D. and R.R.P.; Formal Analysis, S.C.D., T.D. and C.C.C.; Investigation, S.C.D.; Resources, 
C.C.C.; Writing-Original Draft Preparation, S.C.D.; Writing-Review and Editing, S.C.D., R.R.P., T.D. and C.C.; Visualization, R.R.P. and C.C.C.; Supervision, C.C.C.; Project Administration, C.C.C.; Funding Acquisition, C.C.C.

Funding: This research received no external funding.

Acknowledgments: We gratefully acknowledge support for this work from the Faculty of Research and Creative Activity Committee (FRCAC), the Molecular Biosciences (MOBI) PhD program and the Office of Research Services (ORS) of Middle Tennessee State University. We thank Joyce Miller for assistance in obtaining the TEM data. S.C.D. thanks Mulugeta B. Wayu for helpful discussions that inspired this work.

Conflicts of Interest: The authors declare no conflict of interest.

\section{References}

1. Perlstein, T.S.; Gumieniak, O.; Williams, G.H.; Sparrow, D.; Vokonas, P.S.; Gaziano, M.; Weiss, S.T.; Litonjua, A.A. Uric acid and the development of hypertension: The normative aging study. Hypertension 2006, 48, 1031-1036. [CrossRef] [PubMed]

2. Usama, A.A.; El Din, S.; Salem, M.M.; Abdulazim, D.O. Uric acid in the pathogenesis of metabolic, renal, and cardiovascular diseases: A review. J. Adv. Res. 2017, 8, 537-548.

3. Sakhaee, K. Epidemiology and clinical pathophysiology of uric acid kidney stones. J. Nephrol. 2014, 27, 241-245. [CrossRef] [PubMed]

4. Kelley, W.N.; Rosenbloom, F.M.; Henderson, J.F.; Seegmiller, J.E. A specific enzyme defect in gout associated with overproduction of uric acid. Proc. Natl. Acad. Sci. USA 1967, 57, 1735-1739. [CrossRef] [PubMed]

5. Luo, Y.-C.; Do, J.-S.; Liu, C.-C. An amperometric uric acid biosensor based on modified Ir-C electrode. Biosens. Bioelectron. 2006, 22, 482-488. [CrossRef] [PubMed]

6. Perez-Ruiz, F.; Dalbeth, N.; Bardin, T. A review of uric acid, crystal deposition disease, and gout. Adv. Ther. 2015, 32, 31-41. [CrossRef] [PubMed]

7. El Ridi, R.; Tallima, H. Physiological functions and pathogenic potential of uric acid: A review. J. Adv. Res. 2017, 8, 487-493. [CrossRef] [PubMed]

8. Zhang, W.; Doherty, M.; Bardin, T.; Pascual, E.; Barskova, V.; Conaghan, P.; Gerster, J.; Jacobs, J.; Leeb, B.; Lioté, F.; et al. EULAR evidence based recommendations for gout. Part II: Management. Report of a task force of the EULAR standing committee for international clinical studies including therapeutics (ESCISIT). Ann. Rheum. Dis. 2006, 65, 1312-1324. [CrossRef] [PubMed]

9. Khanna, D.; Fitzgerald, J.D.; Khanna, P.P.; Bae, S.; Singh, M.K.; Neogi, T.; Pillinger, M.H.; Merill, J.; Lee, S.; Prakash, S.; et al. 2012 American College of Rheumatology Guidelines for Management of Gout. Part 1: Systematic Nonpharmacologic and Pharmacologic Therapeutic Approaches to Hyperuricemia. Arthritis Care Res. 2012, 64, 1431-1446. [CrossRef] [PubMed]

10. Stack, A.G.; Hanley, A.; Casserly, L.F.; Cronin, C.J.; Abdalla, A.A.; Kernan, T.J.; Murthy, B.V.R.; Hegarty, A.; Hannigan, A.; Nguyen, H.T. Independent and conjoint associations of gout and hyperuricemia with total and cardiovascular mortality. J. Med. 2013, 106, 647-658.

11. Choi, H.K.; Curhan, G. Independent impact of gout on mortality and risk for coronary heart disease. Circulation 2007, 107, 894-900. [CrossRef] [PubMed]

12. Krishnan, E.; Svendsen, K.; Neaton, J.D. Long-term cardiovascular mortality among middle-aged men with gout. Arch. Intern. Med. 2008, 168, 1104-1110. [CrossRef] [PubMed]

13. Kim, K.M.; Henderson, G.N.; Ouyang, X.; Frye, R.F.; Sautin, Y.Y.; Feig, D.I.; Johnson, R.J. A sensitive and specific liquid chromatography-tandem mass spectrometry method for the determination of intracellular and extracellular uric acid. J. Chromatogr. B 2009, 877, 2032-2038. [CrossRef] [PubMed]

14. Wang, J. Carbon-nanotube based electrochemical biosensors: A review. Electroanalysis 2005, 17, 7-14. [CrossRef]

15. Erden, P.E.; Kiliç, E. A review of enzymatic uric acid biosensors based on amperometric detection. Talanta 2013, 107, 312-323. [CrossRef] [PubMed]

16. Wayu, M.B.; Spidle, R.T.; Devkota, T.; Deb, A.K.; Delong, R.K.; Ghosh, K.C.; Wanekaya, A.K.; Chusuei, C.C. Morphology of hydrothermally synthesized $\mathrm{ZnO}$ nanoparticles tethered to carbon nanotubes affects electrocatalytic activity for $\mathrm{H}_{2} \mathrm{O}_{2}$ detection. Electrochim. Acta 2013, 97, 99-104. [CrossRef] [PubMed] 
17. Conway, G.E.; Lamberston, R.H.; Schwarzmann, M.A.; Pannell, M.J.; Kerins, H.W.; Rubenstien, K.J.; Dattelbaum, J.D.; Leopold, M.C. Layer-by-Layer desgin and optimization of xerogel-based amperometric first generation biosensors of uric acid. J. Electroanal. Chem. 2016, 775, 135-145. [CrossRef]

18. Wayu, M.B.; DiPasquale, L.T.; Schwarzmann, M.A.; Gillspie, S.D.; Leopold, M.C. Electropolymerization of B-cyclodextrin onto multi-walled carbon nanotube composite films for enhanced selective detection of uric acid. J. Electroanal. Chem. 2016, 783, 192-200. [CrossRef]

19. Wayu, M.B.; Pannell, M.J.; Leopold, M.C. Layered xerogel films incorporating monolayer-protected cluster networks on platinum-black-modified electrodes for enhanced sensitivity in first-generation uric acid biosensing. ChemElectroChem 2016, 3, 1245-1252. [CrossRef]

20. Wayu, M.B.; Schwarzmann, M.A.; Gillespie, S.D.; Leopold, M.C. Enzyme-free uric acid electrochemical sensors using B-cyclodextrin-modified carboxylic acid-functionalized carbon nanotubes. J. Mater. Sci. 2017, 52, 6050-6062. [CrossRef]

21. Donniah, S.K.; Periakarruppan, P.; Vellaichamy, B. New electrochemical sensor based on a silver-doped iron oxide nanocomposite coupled with polyaniline and its sensing application for picomolar-level detection of uric acid in human blood and urine samples. J. Phys. Chem. B 2018, 122, 3037-3046.

22. Wu, C.; Qiao, X.; Chen, J.; Wang, H.; Tan, F.; Li, S. A novel chemical route to prepare ZnO nanoparticles. Mater. Lett. 2006, 60, 1828-1832. [CrossRef]

23. Bai, H.P.; Lu, X.X.; Yang, Y.H. Hydrogen peroxide biosensor based on electrodeposition of zinc oxide nanoflowers onto carbon nanotubes film electrode. Chin. Chem. Lett. 2008, 19, 314-318. [CrossRef]

24. Baig, N.; Rana, A.; Kawde, A.-N. Modified electrodes for selective detection of biomolecules. Electroanalysis 2018, 30, 2551-2574. [CrossRef]

25. Xing, Y. Synthesis and electrochemical characterization of uniformly-dispersed high loading Pt nanoparticles on sonochemically-treated carbon nanotubes. J. Phys. Chem. B 2004, 108, 19255-19259. [CrossRef]

26. Xing, Y.; Li, L.; Chusuei, C.C.; Hull, R.V. Sonochemical oxidation of multiwalled carbon nanotubes. Langmuir 2005, 21, 4185-4190. [CrossRef] [PubMed]

27. Hull, R.V.; Li, L.; Xing, Y.; Chusuei, C.C. Pt nanoparticle binding on functionalized multiwalled carbon nanotubes. Chem. Mater. 2006, 18, 1780-1788. [CrossRef]

28. Deb, A.K.; Das, S.C.; Saha, A.; Wayu, M.B.; Marksberry, M.H.; Baltz, R.J.; Chusuei, C.C. Ascorbic acid, acetaminophen, and hydrogen peroxide detection using a dendrimer-encapsulated Pt nanoparticle carbon nanotube composite. J. Appl. Electrochem. 2016, 46, 289-298. [CrossRef]

29. Fang, B.; Zhang, C.; Zhang, G. A novel hydrazine electrochemical sensor based on a carbon nanotube-wired ZnO nanoflower-modified electrode. Electrochim. Acta 2009, 55, 178-182. [CrossRef]

30. Park, J.; Regalbuto, J.R. A Simple, Accurate Determination of Oxide PZC and the Strong Buffering Effect of Oxide Surfaces at Incipient Wetness. J. Colloid Interface Sci. 1995, 175, 239-252. [CrossRef]

31. McPhail, M.R.; Sells, J.A.; He, Z.; Chusuei, C.C. Charging Nanowalls: Adjusting the Carbon Nanotube Isoelectric Point via Surface Chemical Functionalization. J. Phys. Chem. C 2009, 113, 14102-14109. [CrossRef]

32. Chusuei, C.C.; Wayu, M. Characterizing functionalized carbon nanotubes for improved fabrication in aqueous solution environments. In Electronic Properties of Carbon Nanotubes/Book 5; Marulanda, J.M., Ed.; InTech: Rijeka, Croatia, 2011; pp. 55-66.

33. Deb, A.K.; Chusuei, C.C. Aqueous solution surface chemistry of carbon nanotubes. In Physical and Chemical Properties of Carbon Nanotubes; Suzuki, S., Ed.; InTech: Rijeka, Croatia, 2013; pp. 263-283.

34. Chusuei, C.C.; Wu, C.-H.; Mallavarapu, S.; Stephen Hou, F.Y.; Hsu, C.-M.; Winiarz, J.G.; Aronstam, R.S.; Huang, Y.-W. Cytotoxicity in the age of nano: The role of fourth period transition metal oxide nanoparticle physicochemical properties. Chem.-Biol. Interact. 2013, 206, 319-326. [CrossRef] [PubMed]

35. Chusuei, C.C.; Wu, C.-H.; Mallavarapu, S.; Stephen Hou, F.Y.; Hsu, C.-M.; Aronstam, R.S.; Huang, Y.-W. Physicochemical structure effects on metal oxide nanoparticulate cytotoxicity. In Recent Progress in Surface and Colloid Chemistry with Biological Applications; Wang, C., Hauserman, B., Eds.; American Chemical Society: Washington, DC, USA, 2015; Volume 1215, pp. 137-155.

36. Weiler, M.; Sattel, S.; Jung, K.; Ehrhardt, H.; Veerasamy, V.; Robertson, J. Highly tetrahedral, diamond-like amorphous hydrogenated carbon prepared from a plasma beam source. Appl. Phys. Lett. 1994, 64, 2797-2799. [CrossRef]

37. McCafferty, E.; Wightman, J.P. Determination of the concentration of surface hydroxyl groups on metal oxide films by a quantitative XPS method. Surf. Interface Anal. 1998, 26, 549-564. [CrossRef] 
38. Haber, J.; Stoch, J.; Ungier, L. X-ray photoelectron spectra of oxygen in oxides of cobalt, nickel, iron, and zinc. J. Electron Spectrosc. Relat. Phenom. 1976, 9, 459-467. [CrossRef]

39. Kanik, F.E.; Kolb, M.; Timur, S.; Bahadir, M.; Toppare, L. An amperometric acetylcholine biosensor based on a conducting polymer. Int. J. Biol. Macromol. 2013, 59, 111-118. [CrossRef] [PubMed]

40. Langer, D.W.; Vesely, C.J. Electronic core levels of zinc chalcogenides. Phys. Rev. B 1970, 2, 4885-4892. [CrossRef]

41. Strohmeier, B.R.; Hercules, D.M. Surface spectroscopic characterization of the interaction between zinc ions and $\gamma$-alumina. J. Catal. 1984, 86, 266-279. [CrossRef]

42. Wayu, M.B.; King, J.E.; Johnson, J.A.; Chusuei, C.C. A zinc oxide carbon nanotubed based sensor for in situ monitoring of hydrogen peroxide in swimming pools. Electroanalysis 2015, 27, 2552-2558. [CrossRef]

43. Zanello, P. Inorganic Electrochemistry: Theory, Practice and Application; Royal Society of Chemistry: London, UK, 2003.

44. Dresselhaus, M.S.; Dresselhaus, G.; Avouris, P. Carbon Nanotubes: Synthesis, Structure, Properties and Applications; Springer: New York, NY, USA, 2001.

45. Lehman, J.H.; Terrones, M.; Mansfield, E.; Hurst, K.E.; Meunir, V. Evaluating the characteristics of multiwall carbon nanotubes. Carbon 2011, 49, 2581-2602. [CrossRef]

46. Kim, J.H.; Hwang, J.Y.; Hwang, H.R.; Kim, H.S.; Lee, J.H.; Seo, J.W.; Shin, U.S.; Lee, S.H. Simple and cost-effective method of highly conductive and elastic carbon nanotube/polydimethylsiloxane composite for wearable electronics. Sci. Rep. 2018, 8, 1375. [CrossRef] [PubMed]

47. Yamanaka, H.; Togashi, R.; Hakoda, M.; Terai, C.; Kashiwazaki, S.; Dan, T.; Kamatani, N. Optimum range of serum urate concentrations to minimize risk of gouty attacks during anti-hyperuricemic treatment. Adv. Exp. Med. Biol. 1998, 431, 13-18. [PubMed]

48. Kuo, C.C.; Weaver, V.; Fadrowski, J.J.; Lin, Y.S.; Guallar, E.; Navas-Acien, A. Arsenic exposure, hyperuricemia, and gout in US adults. Environ. Int. 2015, 76, 32-40. [CrossRef] [PubMed]

49. Sposito, G. On points of zero charge. Environ. Sci. Technol. 1998, 32, 2815-2819. [CrossRef]

50. Lide, D.R. (Ed.) CRC Handbook of Chemistry and Physics, 71st ed; CRC Press: Boca Raton, FL, USA, 1990.

51. Szakács, Z.; Noszál, B. Determination of dissociation constants of folic acid, methotrexate, and other photolabile pterdines by pressure-assisted capillary electrophoresis. Electrophoresis 2006, 27, 3399-3409. [CrossRef] [PubMed]

52. Zhang, T.; Lang, Q.; Zeng, L.; Li, T.; Wei, M.; Liu, A. Substituent effect on the oxidation peak potentials of phenol derivatives at ordered mesoporous carbons modified electrode and its application in determination of acidity coefficients $\left(\mathrm{pK}_{\mathrm{a}}\right)$. Electrochim. Acta 2014, 115, 283-289. [CrossRef]

53. Perrin, D.D. Ionization Constants of Inorganic Acids and Bases in Aqueous Solution, 2nd ed.; Pergamon: Oxford, UK, 1982.

54. Ngai, K.S.; Tan, W.T.; Zainal, Z.; Zawawi, R.M.; Zidan, M. Voltammetry detection of ascorbic acid at glassy carbon electrode modified by single-walled carbon nanotube/zinc oxide. Int. J. Electrochem. Sci. 2013, 8, 10557-10567.

55. Raoof, J.B.; Teymoori, N.; Khalilzadeh, M.A.; Ojani, R. A high sensitive electrochemical nanosensor for simultaneous determination of glutathione, NADH and folic acid. Mater. Sci. Eng. C 2015, 47, 77-84. [CrossRef] [PubMed]

(c) 2018 by the authors. Licensee MDPI, Basel, Switzerland. This article is an open access article distributed under the terms and conditions of the Creative Commons Attribution (CC BY) license (http://creativecommons.org/licenses/by/4.0/). 